\title{
Políticas sociais locais e os desafios da participação citadina
}

\author{
Local social policies and the challenges \\ of citizens participation
}

Pedro R. Jacobi 1

\footnotetext{
1 Programa de

Pós-Graduação

em Ciência Ambiental,

Faculdade de Educação

da Universidade de São

Paulo. Rua Agisse 172/173.

05439-010 São Paulo SP.

prjacobi@terra.com.br
}

\begin{abstract}
This text presents an analysis on the dimensions of participation and the possibilities of enlargement of citizenship, having as reference public policies of education, health and environment at the local level. The articulating theme is popular participation in public administration and the qualitative transformations in the relationship between State and civil society, as a reference of a turning point and strengthening of public policies centered that emphasize active citizenship. Our challenge is to analyze, on one side, the impacts of participatory practices that point out to new configurations of the quality of citizenship, and, on the other side, the characterization of those barriers that have to be overcome to enable the multiplication of management experiences that articulate efficiently complexity and democracy. The analysis is centered on the strengthening of the public space and the opening of public administration to the participation of Civil Society in the formulation of public policies, and in the always complex and contradictory institutionalization of innovative participatory practices that establish ruptures with the existing process.
\end{abstract}

Key words Participation, Citizenship, Social policies, State, Civil society
Resumo O objetivo deste texto é aprofundar a reflexão em torno das dimensões da participação e das possibilidades de ampliação da cidadania. O tema articulador é a participação popular na gestão pública e as transformações qualitativas na relação Estado/Sociedade civil. O desafio que nos propomos é o de analisar, de um lado, os impactos de práticas participativas que apontam, a partir da manifestação do coletivo, para uma nova qualidade de cidadania que institui o cidadão como criador de direitos para abrir novos espaços de participação sociopolítica; e, de outro, os aspectos que configuram as barreiras que precisam ser superadas para multiplicar iniciativas de gestão que articulam eficazmente a complexidade com a democracia. A análise se centra no fortalecimento do espaço público e na abertura da gestão pública à participação da sociedade civil na elaboração de suas políticas públicas; e na sempre complexa e contraditória institucionalização de práticas participativas inovadoras que marcam rupturas com a dinâmica predominante, ultrapassando as ações de caráter utilitarista e clientelista.

Palavras-chave Participação, Cidadania, Políticas sociais, Estado, Sociedade civil 


\section{Introdução}

Este texto propõe o aprofundamento da reflexão em torno das dimensões da participação e das possibilidades de ampliação da cidadania, tendo como referência experiências de gestão em torno da educação, da saúde e do meio ambiente. Estes permitem, a partir da sua diversidade, estabelecer elementos de comparação sobre o papel dos diversos atores intervenientes, num contexto onde ainda convivem as formas tradicionais de gestão e as experiências inovadoras que começam a se legitimar aos olhos da população.

O tema articulador é a participação popular na gestão pública e as transformações qualitativas na relação Estado/sociedade civil, como referência de um ponto de inflexão e reforço das políticas públicas centradas na ampliação da cidadania ativa.

Esta escolha decorre da necessidade sentida de aprofundar a reflexão em torno de um tema que, dada a sua atualidade, exige análises sobre os seus alcances e limites, mas principalmente sobre a potencialidade implícita na constituição de uma esfera pública não estatal. Isto se consubstancia através da criação de instituições voltadas para a produção e reprodução de políticas públicas que não são controladas pelo Estado, mas têm um caráter indutivo, fiscalizador e controlador sobre este.

O desafio proposto é realizarmos a análise não só dos impactos de práticas participativas que apontam, a partir da manifestação do coletivo, para uma nova qualidade de cidadania que institui o cidadão como criador de direitos para abrir novos espaços de participação sociopolítica, mas também dos aspectos que configuram as barreiras que precisam ser superadas para multiplicar iniciativas de gestão capazes de articular eficazmente a complexidade com a democracia.

Observa-se que a análise das práticas participativas traz à tona, na maior parte das vezes, uma leitura que oscila, de um lado, entre a apologia e o voluntarismo e, do outro, entre a indiferença e a subestimação, pouco contribuindo para a problematização dos complexos e diversificados processos em curso.

Existe, portanto, uma crescente necessidade de entender as ambigüidades dos processos sociais e os arranjos possíveis, mas principalmente os limites, tendo como referência uma análise qualitativa das práticas sociais e das atitudes dos diversos atores envolvidos, tanto nas experiências que inovam na gestão da coisa pública, co- mo nas que mantêm inalteradas as práticas tradicionalmente desenvolvidas.

Os temas aqui desenvolvidos estão organizados de forma a introduzir o leitor em um universo de questões que, apesar da sua multiplicidade, se centram na associação entre cidadania, democracia participativa, governabilidade e sustentabilidade.

A análise focaliza o fortalecimento do espaço público e a abertura da gestão pública à participação da Sociedade civil na elaboração de suas políticas públicas; e a sempre complexa e contraditória institucionalização de práticas participativas inovadoras que marcam rupturas com a dinâmica predominante, ultrapassando as ações de caráter utilitarista e clientelista.

Nas conclusões apresentamos, com base nas análises desenvolvidas, uma reflexão sobre os alcances e limites da participação. Isto é feito a partir dos resultados dos estudos que analisam a gestão como um todo pela voz dos atores intervenientes, com particular ênfase no impacto das engenharias institucionais inovadoras e o significado das mudanças qualitativas introduzidas no cenário político brasileiro.

\section{Reflexões em torno da engenharia institucional para uma cidadania ativa}

Na América Latina, a luta pela conquista de espaços para aumentar a participação social é, sem dúvida, um dos aspectos mais desafiadores para a análise sobre os alcances da democracia nas relações entre o nível local de governo e a cidadania.

Desde o início da década de 1990 e até hoje a participação nas suas diversas dimensões vem sendo amparada e institucionalizada na América Latina dentro dos marcos das democracias representativas. A participação popular se transforma no referencial de ampliação das possibilidades de acesso dos setores populares dentro de uma perspectiva de desenvolvimento da sociedade civil e de fortalecimento dos mecanismos democráticos, mas também de garantia da execução eficiente de programas de compensação social no contexto das políticas de ajuste estrutural e de liberalização da economia e de privatização do patrimônio do Estado. Entretanto, o que se observa é que, no geral, as propostas participativas ainda permanecem mais no plano da retórica do que na prática.

Poucas são, de fato, as experiências de gestão municipal que assumem uma radicalidade 
democrática na gestão da coisa pública, assim como ampliam concretamente o potencial participativo.

A análise dos processos existentes está permeada pelos condicionantes da cultura política, tanto do Brasil como dos demais países da América Latina, marcados por tradições estatistas, centralizadoras, patrimonialistas e, portanto, por padrões de relação clientelistas, meritocráticos e de interesses criados entre Sociedade e Estado. Entretanto, estes condicionantes não têm sido necessariamente um fator impeditivo para a emergência de uma diversidade de formas de participação dos setores populares, em que, com freqüência, muitas se situam no escopo das práticas no contexto das tradições anteriormente descritas, enquanto outras as contradizem abertamente.

Ao identificar a participação citadina como uma forma diferenciada da democracia representativa - a que passa pelos partidos políticos, eleições e integração formal dos governos -, pensamos o tema a partir da sua dimensão cotidiana e do seu impacto societário. Entendemos que a participação pode assumir duas faces: uma que coloca a sociedade em contato com o Estado; e outra que a reconcentra em si mesma, buscando seu fortalecimento e desenvolvimento autônomo. O que está efetivamente em pauta é o alcance da democratização do aparelho estatal, notadamente quanto à sua publicização. Dito em outros termos, trata-se de pensar sobre a participação da população e a sua relação com o fortalecimento de práticas políticas e de constituição de direitos que transcendem os processos eleitorais e seus freqüentemente ambíguos e/ou contraditórios reflexos sobre a cidadania.

O tema dos direitos e da cidadania assume dimensão relevante no contexto deste referencial analítico, na medida em que permite aprofundar o significado do impacto e das transformações ocorridas na relação entre sociedade civil e Estado desde meados da década de 1980.

No limiar do século 21 , as contradições em torno do uso dos conceitos têm se acentuado, em virtude do que Santos (1996) entende como a continuidade do uso de uma análise dos processos de transformação social do fim do século $X X$ com recurso a quadros conceptuais desenvolvidos no século XIX e adequados aos processos sociais então em curso.

A nossa reflexão também se apóia nos conceitos formulados por Arato e Cohen (1994), e Avritzer (1993), que tomam como ponto de partida analítico a revitalização da sociedade civil.
Nossa referência são as teorias contemporâneas de sociedade civil, que enfatizam a idéia de organização da sociedade como autodefesa (Arato et al., 1994) e as possibilidades e limites dos projetos de ampliação da democracia, tomando como base processos de democratização em diversos contextos (notadamente na Europa do Leste e na América Latina) onde atores sociais e políticos identificam a sua ação como parte da reação da sociedade civil ao Estado.

A esfera pública é apontada por Habermas como ponto de encontro e local de disputa entre os princípios divergentes de organização da sociabilidade; e os movimentos sociais se constituiriam nos atores que reagem à reificação e burocratização dos domínios de ação estruturados comunicativamente, defendendo a restauração das formas de solidariedade postas em risco pela racionalização sistêmica.

Arato e Cohen definem a sociedade política e econômica como um instrumento ofensivo da sociedade civil contra sua própria colonização pelo sistema. Para Avritzer (1993), a inclusão dos movimentos democratizantes estruturados interativamente no interior do marco teórico habermasiano e a possibilidade de sua extensão aos países do Leste e da América Latina permitem entender os movimentos democráticos nestes países como reação aos processos de fusão entre Estado e mercado e Estado e sociedade.

A possibilidade de alterar a institucionalidade pública está associada às demandas que se estruturam na sociedade. Já a esfera pública representa a construção da viabilidade ao exercício da influência da sociedade nas decisões públicas assim como coloca uma demanda de publicização no Estado. O que está em jogo é a necessidade de atualização dos princípios éticopolíticos da democracia, onde o fortalecimento do tecido associativo potencializa o fortalecimento da democracia no resto das esferas da vida social. Para Putnam (1994), as práticas sociais que constroem cidadania representam a possibilidade de se constituir num espaço privilegiado para cultivar a responsabilidade pessoal, a obrigação mútua e a cooperação voluntária. As práticas sociais que lhe são inerentes relacionam-se com a solidariedade, e no encontro entre direitos e deveres. A ampliação da esfera pública ocasiona uma demanda à sociedade para obtenção de uma maior influência sobre o Estado, tanto como sua limitação, assumindo que a autonomia social supõe transcender as assimetrias na representação social, assim como modificar as relações sociais em favor de uma 
maior auto-organização social (Cunill Grau, 1998).

A redefinição das relações entre Estado e sociedade civil no Brasil, no final dos anos 70, implica a constituição, com muitos percalços, de uma esfera societária autônoma.

Os atores sociais que emergem na sociedade civil após 1970, à revelia do Estado, criaram novos espaços e formas de participação e relacionamento com o poder público. Estes espaços foram construídos, tanto pelos movimentos populares como pelas diversas instituições da sociedade civil que articulam demandas e alianças de resistência popular e lutas pela conquista de direitos civis e sociais. Os movimentos não só tiveram papel relevante no estabelecimento de estruturas democráticas fundamentais propícias à participação popular, mas também exerceram um impacto substancial sobre as formações normativas do eleitorado, e, portanto, sobre a arena política formal. Ao gerarem novos elementos de conhecimento e de cultura, muitos movimentos imprimiram sua marca e orientaram sua ação pela defesa de práticas pautadas pela sua autonomia, pela necessidade de tornar visível a sua capacidade de auto-organizar-se e de desenvolver a democracia direta, transformando as carências do seu entorno de moradia em práticas reivindicatórias.

Os anos 80 trazem uma complexidade crescente nas interações dos movimentos com os órgãos públicos e uma importância maior das assessorias especializadas e das articulações interinstitucionais. A crescente politização da esfera privada permite a construção de novos padrões de valores, configurando freqüentemente uma vinculação ideológica e política entre a necessidade e seus condicionantes estruturais. $\mathrm{O}$ processo de envolvimento dos moradores e a cada vez mais freqüente resposta do poder público face às demandas, somada à participação dos profissionais e articuladores sociais e/ou assessores, possibilitam a acumulação de conhecimento em torno das questões reivindicadas, vinculando-as às pautas institucionalizadas da sociedade e criando condições para a formulação de demandas junto aos órgãos públicos (Jacobi, 1990).

Deve-se destacar também o significado que as transformações do processo político mais amplo provocam na feição do movimento, na medida em que estes passam a ser reconhecidos cada vez mais como interlocutores válidos. Muitos movimentos apontam, a partir da reposição do coletivo, para uma qualidade dife- renciada de participação na gestão da coisa pública, na qual a representação não resume todo o esforço de organização, mas configura uma parte de um processo em que a população cria as condições para influenciar a dinâmica de funcionamento de um órgão do Estado (Jacobi, 1989).

Com as mudanças político-institucionais que ocorrem a partir de 1983, os movimentos passam a enfrentar a tensão face à institucionalização, configurada a partir da sua desconfiança face à participação política institucional.

Entretanto a sua crescente importância no processo político se reflete com a eleição de prefeitos progressistas, na medida em que os movimentos não só exercem pressão sobre a arena política, mas ampliam seu espaço de inserção e conseguem também influenciar, às vezes, a agenda de gestões progressistas. Isto se verifica pela expansão do seu potencial participativo em conselhos de gestão tripartite, comissões de planejamento e outras formas específicas de representação.

Deve ser registrada a multiplicidade de dinâmicas participativas nas estruturas de conselhos e colegiados criados a partir da Constituição de 1988. O fato diferenciador destas transformações é, segundo Melucci (1994), o fortalecimento de novas instituições, as mudanças no relacionamento do quadro de pessoal com os usuários e a nova mentalidade sobre a gestão da coisa pública, como aspectos constitutivos de uma nova cultura política. Nos anos 90, além das práticas participativas inovadoras que se institucionalizam cada vez mais, surgem novos movimentos baseados em ações solidárias alternativas centradas em questões éticas ou de revalorização da vida humana, como é o caso da Ação da Cidadania contra a Fome, a Miséria e pela Vida (Jacobi, 1996).

No Brasil, a reflexão sobre a cidadania se centra nos obstáculos à sua extensão, decorrentes da cultura política tradicional, e das perspectivas da sua transformação. A nova dimensão da cidadania inclui, de um lado, a constituição de cidadãos no papel de sujeitos sociais ativos, e, de outro lado, para a sociedade como um todo, um aprendizado de convivência com esses cidadãos emergentes que recusam permanecer nos lugares que thes foram definidos social e culturalmente.

A partir de 1983, aumenta a participação dos estados e municípios nos fundos federais, o que tem resultado, entretanto, num conjunto fragmentado e inorgânico de programas e pro- 
jetos governamentais que configuram um padrão altamente diferenciado e heterogêneo na implementação da descentralização, oscilando entre iniciativas que inovam na lógica da gestão com participação e as que mantêm as fórmulas tradicionais de clientelismo e patrimonialismo. Nessa direção, um dos aspectos mais complexos e questionáveis está relacionado com uma postura institucional de estimular a participação como um fator de substituição, buscando envolver cada vez mais, e de forma direta, os cidadãos na produção e/ou gerenciamento dos serviços públicos.

No contexto da transição pós-democrática no Brasil e pelas pressões de uma sociedade civil mais ativa e mais organizada, foram sendo criados novos espaços públicos de interação, mas principalmente de negociação. Nesse contexto a participação citadina emerge, principalmente como referencial de rupturas e tensões, e as práticas participativas associadas a uma mudança qualitativa da gestão assumem visibilidade pública e repercutem na sociedade.

As transformações na dinâmica de gestão e o fortalecimento de práticas que tornam legítima a participação citadina estão, direta ou indiretamente, associadas à necessidade de imprimir também maior eficiência à ação governamental.

As transformações político-institucionais e a ampliação de canais de representatividade dos setores organizados para atuarem junto aos órgãos públicos, como conquista dos movimentos organizados da sociedade civil, mostram a potencialidade de construção de sujeitos sociais identificados por objetivos comuns na transformação da gestão da coisa pública, associada à construção de uma nova institucionalidade.

A formulação mais recorrente está estruturada em torno do aprofundamento do processo democrático, e do seu impacto na ampliação da capacidade de influência sobre os diversos processos decisórios em todos os níveis da atividade social e das instituições sociais. A participação social se enquadra no processo de redefinição entre o público e o privado, dentro da perspectiva de redistribuir o poder em favor dos sujeitos sociais que geralmente não têm acesso. De um lado, a participação é identificada com os argumentos da democratização que têm como referência o fortalecimento dos espaços de socialização, de descentralização do poder e de crescente autonomização das decisões, portanto, enfatizando a importância de um papel mais autônomo dos sujeitos sociais. O outro enfo- que aborda a participação, a partir da criação de espaços e formas de articulação do Estado com os sujeitos sociais, configurando um instrumento de socialização da política, reforçando o seu papel como meio para realizar interesses e direitos sociais que demandam uma atuação pública.

A concepção conciliar passa a ter uma presença crescente no Brasil a partir da legitimação do papel inovador dos diversos tipos de conselhos, como facilitadores da presença da sociedade civil na gestão pública. A institucionalização da participação ampliada ou neocorporativa ocorre através da inclusão de organizações comunitárias e movimentos populares nos conselhos populares e fóruns, dentre os principais. Isto abre uma arena institucional para a inclusão de grupos sociais, onde todos os setores interessados numa determinada política pública possam discutir os seus objetivos num fórum com regras claras e transparentes, podendo representar também um avanço na promoção do exercício efetivo de uma cidadania ativa.

$\mathrm{O}$ arranjo institucional participativo ampliado se consolida na medida em que viabiliza a capacidade dos grupos de interesse de influenciar, direta ou indiretamente, a formulação e gestão de políticas públicas. A ampliação da oferta citadina no processo assume um caráter diferenciador, não só quanto à legitimidade, mas principalmente quanto à garantia de governabilidade e de democratização da gestão dos bens públicos. As práticas participativas representam uma efetiva possibilidade de ampliação do espaço do público. Muitas vezes, em nome de supostos "interesses públicos" mantêm-se estruturas e gestões estatais verticalizadas e autoritárias, que servem para garantir interesses corporativos, para a privatização de recursos orçamentários e para a concessão de benefícios políticos restritos a determinados grupos e indivíduos.

A consolidação de propostas participativas representa a potencialização e a ampliação de práticas comunitárias, através do estabelecimento e ativação de um conjunto de mecanismos institucionais que reconheçam direitos efetivamente exercitáveis e estimulem estratégias de envolvimento e co-responsabilização. Nesse sentido, um dos maiores desafios de uma proposta participativa ampliada é o de garantir a definição de critérios de representação, de forma a impedir tanto a sua manipulação por grupos guiados por interesses particularizados, como a possibilidade da sua instrumentalização pela administração pública. 


\section{Políticas sociais, descentralização e participação: o desafio de superar a lógica tradicional e de construir uma nova institucionalidade}

Nas experiências municipais de gestão de políticas sociais, o executivo se constitui no espaço privilegiado das decisões, exercendo uma função catalisadora pouco inovadora. As dificuldades na cooperação entre estado e município impedem a ampliação do poder local na gestão, o que, reforçado pela inoperância das instâncias participativas, reflete a prevalência dos canais informais e da lógica da cultura política tradicional destas administrações.

Nas experiências de prefeituras progressistas, e tomando como referência o caso de São Paulo, durante a primeira gestão do PT (19891992), embora não houvesse um projeto plenamente estruturado sobre como viabilizar a participação popular nos diversos aspectos da administração municipal, é inegável que existiu vontade política de incorporar a participação da população nas diversas instâncias criadas para a tomada de decisões.

O ponto de partida da gestão era o programa de governo apresentado na campanha baseado numa proposta "democrática e popular de governo", centrado num compromisso de inverter prioridades, reorientando os investimentos públicos de modo a atender prioritariamente as necessidades e os direitos sociais dos setores mais carentes da população.

A concepção de participação popular é parte componente de uma estratégia de ampliação de sua base social e política, que visa fortalecer uma forma de governar a cidade introduzindo novos atores, integrando a população excluída e segregada da cidade a um processo democrático de gestão. O marco de referência está dado pela enorme desigualdade socioeconômica entre as classes sociais, pelo vazio de instituições sociais e políticas, pelos problemas de representação política e pela necessidade de avanços não só na democratização das relações sociais, mas principalmente na consolidação da cidadania social.

A questão da participação encerrava um conjunto de interrogações que só podiam ser respondidas pela ativação de uma engenharia institucional que tinha, como uma de suas referências, a experiência acumulada pelos diversos movimentos sociais. E estes traziam, implicitamente, uma visão de participação na forma de democracia direta ou de participação entre iguais. Um dos grandes desafios era romper com a prática do clientelismo e da troca de favores, embora não se pudesse escamotear que a grande maioria das organizações sociais ou é relativamente frágil, ou extremamente especializada, e que a população em geral tende a estabelecer relações individuais e diretas com a administração.

A gestão se inicia com a intenção de governar a partir de uma proposta fortemente ancorada no ideário político-partidário presente na campanha eleitoral. Tal ideário centra-se no estímulo e apoio às iniciativas da população, com o objetivo de criar Conselhos Populares autônomos, mas resulta também de uma concepção predominante nos setores populares mais organizados, notadamente na área de saúde e educação.

A experiência de governo na maioria das administrações petistas, tanto nas que foram reeleitas como nas que foram derrotadas em 1992, mostra a visão pouco realista que existia em torno da participação - a panacéia dos Conselhos Populares. Trata-se de tema da maior complexidade e que está diretamente vinculado à participação em instâncias conciliares e às formas de representação. O esforço do executivo é de reduzir ao máximo o voluntarismo, o espontaneismo e a aleatoriedade das práticas participativas, procurando implantar uma dinâmica participativa mais realista e adequada aos limites que retardam a promoção de avanços nesta questão.

Em São Paulo, a democratização da gestão educacional tem na participação da sociedade um componente prioritário. A orientação é para que a comunidade atue principalmente como interlocutora privilegiada na gestão da política tanto no nível local como municipal, buscando reduzir, na medida do possível, os aspectos fisiológicos e paternalistas freqüentemente implícitos em projetos participativos. A dinamização das instâncias participativas, apesar da resistência do funcionalismo, possibilitou um avanço efetivo na autonomia administrativa, financeira e pedagógica das escolas, refletindo diferenças entre regiões. Os alcances da participação, apesar do estímulo da administração, estavam muito relacionados ao nível de mobilização, organização e pressão existentes nos bairros. Os Conselhos de Escola foram incentivados pela administração, e seus resultados foram diversificados, principalmente pela inexistência de um ethos efetivamente participacionista na população. A busca de uma participação quali- 
ficada é vista pela administração como referência fundamental de ativação da cidadania. Não obstante, avanços mais substantivos no relacionamento escola-comunidade foram dificultados por resistências, principalmente dos diretores.

O desafio proposto era o rompimento com as relações de poder existentes, valorizando e resgatando a noção de escola, acomodando a demanda e estimulando mecanismos de co-responsabilização da população na dinâmica da gestão, na medida que estava em jogo o protagonismo, principalmente dos setores mais excluídos. As resistências se centravam, principalmente, no preconceito e no questionamento, pelo corpo diretivo e docente, sobre o caráter deliberativo do Conselho e sobre a descentralização do poder, cuja divisão provocou claras resistências.

A participação estava muito vinculada à noção de utilidade/objetividade daquilo que era discutido e proposto, refletindo as dificuldades de romper com a cultura política predominante, apesar do esforço da gestão em introduzir uma nova qualidade do trabalho na educação.

A iniciativa de abrir canais de participação cria espaço para um importante questionamento da relação entre estado e sociedade. Em primeiro lugar, faz emergir a necessidade de a comunidade, através de formas organizativas e representativas, enfrentar sua relação com as propostas de participação implantadas pela administração, dentro do conceito de democratizar e inovar na gestão da coisa pública. As dinâmicas de participação implantadas possibilitam um aumento do grau de informação sobre o funcionamento dos serviços e da administração. Isto reforça a sua razão de ser como instâncias com bases setoriais e territoriais, de concretização de um exercício de controle mais permanente e consistente da coisa pública pelos usuários, e representa uma referência de inovação e de construção de novas identidades dos atores sociais envolvidos.

Embora uma estrutura participativa tenha sido implantada no âmbito local, foram grandes as dificuldades para institucionalizar a proposta, na medida em que apesar da orientação e do suporte fornecido pela administração para a implantação e consolidação dos colegiados nos diversos níveis, as instâncias descentralizadas mostraram resultados bastante diferenciados quanto ao grau de participação. Além disso, freqüentemente, o baixo nível de institucionalização esteve vinculado às resistências corporativas à implementação de práticas participativas, sempre que vinham à tona questões como controle, fiscalização e deliberação por parte da comunidade.

Os resultados heterogêneos no conjunto da cidade refletem as dificuldades de se modificar uma cultura burocrática e centralizadora, que coloca entraves à democratização dos serviços e aos mecanismos de fiscalização e controle social da administração pública. A dinamização das instâncias colegiadas, como os Conselhos de Escola, representa a possibilidade de estimular formas de cooperação com setores organizados e não-organizados da cidadania nas quais não se percam de vista alguns temas essenciais à democratização da gestão. Estes temas se centram na possibilidade de reforçar a capacidade de crítica e de intervenção dos setores populares através de um processo pedagógico e informativo de base relacional; e a capacidade de multiplicação e aproveitamento de potencial dos cidadãos no processo decisório dentro de uma lógica não cooptativa.

A experiência de São Paulo mostra que os pais avançaram mais do que os professores na assimilação da proposta. Criaram-se condições para que as relações com a clientela da escola se tornassem mais responsáveis. E demonstrou-se a viabilidade; apesar das grandes resistências, de construção de um espaço público onde o aprendizado da cidadania ativa assume papel central. Embora uma estrutura participativa tenha sido implantada no âmbito local, foram grandes as dificuldades para se institucionalizar a proposta. As resistências corporativas vinculam-se à implementação de práticas participativas, sempre que vêm à tona questões como controle, fiscalização e deliberação por parte da comunidade.

$\mathrm{Na}$ gestão da saúde, o grande desafio que se impunha era de fazer com que os funcionários superassem o medo da participação popular, do fato de seu serviço ser fiscalizado e da população estar mais presente no seu cotidiano, notadamente nos problemas de recursos humanos. A significativa falta de entendimento pelos funcionários sobre o alcance da abertura de canais tem como conseqüência o seu desconhecimento acerca de direitos e deveres.

As dificuldades de implantação das comissões gestoras e de sua legitimação, principalmente nas áreas mais carentes e desmobilizadas da cidade, decorrem em grande parte das deficiências da máquina administrativa - dificuldades de abastecimento de insumos médicos, de lotação de pessoal e a falta de eqüidade na relação da periferia com o resto do município. Ape- 
sar do esforço de garantir uma participação popular pautada pela transparência, respeitando-se a autonomia dos movimentos populares, quando existentes, os alcances são bastante limitados.

As complexidades da participação também são avaliadas, como resultado de um desestímulo da população usuária face aos poucos resultados positivos e à lentidão na resposta da administração frente às demandas dos setores mais carentes, refletindo-se numa dificuldade na hierarquização dos problemas da população.

A iniciativa de abrir canais de participação deixa espaço para problematizar em torno da relação entre estado e sociedade. Isto traz à tona a necessidade de os usuários, através das suas formas de organização e representação, enfrentarem sua relação com propostas de participação implantadas pela administração dentro da sua concepção de democratização da gestão e de inovação da gestão da coisa pública. O rol das comissões gestoras se insere na lógica que preside a formulação da proposta de participação, como um processo educativo no qual busca não só envolver o funcionalismo, mas fortalecer a consciência de cidadania da população para que esta possa assumir, de forma crescente, o papel de sujeito na definição das diretrizes de gestão administrativa da cidade.

O aumento do grau de informação sobre o funcionamento dos serviços e da administração reforça a razão de ser das comissões gestoras como instâncias com bases setoriais e territoriais de consolidação de um exercício de controle mais permanente e consistente da coisa pública pelos usuários. Além disso, deve-se enfatizar que as comissões gestoras, assim como outras instâncias de participação implantadas, representam a referência da inovação e da construção de novas identidades dos atores sociais envolvidos. Trata-se de um estímulo à participação ativa baseado no pressuposto de estimular a co-responsabilização dos usuários e uma disponibilidade para maior interlocução e uma permeabilidade das propostas populares junto à administração.

Para romper com o círculo vicioso, vinculado às dificuldades relacionadas à dinâmica de gestão dos recursos humanos e à mudança cultural que representava, desenvolve-se um grande esforço para implantar uma nova qualidade de trabalho que estimule, à imagem e semelhança dos usuários, uma coresponsabilização e uma motivação para construir e consolidar uma nova prática de atenção à saúde.

O resultado deste processo revela o significado da vontade política e de uma concepção de governo baseada na ativação da cidadania e do risco assumido da inovação - resultado da permeabilidade das propostas populares junto à administração - e de construção de novas identidades e de sujeitos portadores de direitos num contexto permeado pela prevalência de práticas clientelistas e de posturas conservadoras na gestão da coisa pública.

Entretanto, a precária institucionalização da proposta junto aos usuários, as dificuldades do enraizamento da experiência de gestão (no âmbito dos próprios movimentos sociais em virtude das práticas mobilizatórias não serem uniformes nas diversas regiões da cidade), e o predomínio de uma visão imediatista em detrimento de uma concepção mais abrangente centrada na participação possibilitam o desmonte de forma radical da política existente. Concorre decisivamente para esse desmonte a introdução de uma proposta privatizante que estimulou a expansão de uma política de saúde. Desvinculada do SUS, essa política de saúde viabiliza a consolidação de uma rede de corrupção que deteriora totalmente o sistema municipal de saúde entre 1993 e 2001, provocando uma total degradação na qualidade dos serviços. O espaço para que isto ocorra resulta da pouca consolidação de um tecido associativo mais predisposto a reivindicar e preservar um direito adquirido de interferir na gestão. E isso facilita o esvaziamento dos instrumentos descentralizadores e de participação existentes, retomando a tradição da lógica centralizada de gestão.

\section{Participação dos cidadãos - a necessária busca da co-responsabilização}

A institucionalização da participação é permeada de dificuldades decorrentes da heterogeneidade dos grupos comunitários e associativos, o que torna complexos os problemas de representação, criando tensões quanto aos critérios de escolha, acirrando a concorrência e trazendo à tona a pressão dos grupos organizados no sentido de reforço das práticas neocorporativas. Isso provoca, freqüentemente, um esvaziamento destes mecanismos de decisão coletiva.

Atualmente diversas experiências, e notadamente a de Porto Alegre, reforçam uma concepção de democracia que articula representação política e participação direta como resposta possível à privatização prevalecente na gestão da coisa pública. $\mathrm{O}$ discurso predominante acentua a importância da convergência de práticas, da socialização da política, do caráter oscilante da participação, da importância da institucionalidade, da convivência com o sistema repre- 
sentativo existente e da necessidade de governar para toda a cidade.

A análise do caso de São Paulo mostra que o desafio para se garantir a eficácia e continuidade de políticas públicas de caráter progressista é o reforço dos meios para envolver a população e manter o seu interesse, e para dimensionar adequadamente os arranjos institucionais. A sua descontinuidade reforça o argumento de que gestão democrática e participação popular requerem uma forma combinada de fortalecimento das formas de organização da sociedade civil, uma mudança na correlação de forças, uma transformação qualitativa dos padrões de gestão, enfim um processo real de democratização do Estado e da sua gestão. Esta transformação requer o que Arato e Cohen (1994) definem como a existência de uma sociedade civil organizada, diferenciada e adequadamente defendida, capaz de influenciar o Estado e em condições de garantir a manutenção de direitos essenciais e de monitorar e influenciar os processos que se regulam pela lógica sistêmica.

O complexo processo de construção da cidadania no Brasil num contexto de agudização das desigualdades é perpassado por um conjunto de questões que necessariamente implicam a superação das bases constitutivas das formas de dominação e de uma cultura política baseada na tutela, no clientelismo e no patrimonialismo político. A constituição de cidadãos, como sujeitos sociais ativos, se consubstancia a partir da transformação das práticas sociais existentes e na sua substituição pela construção de novas formas de relação, que têm na participação um componente essencial. O enfrentamento do patrimonialismo político é uma tarefa complexa e demorada em virtude do enraizamento das práticas de instrumentalização. $\mathrm{O}$ desafio que se coloca é o de construir novos hábitos, de neutralizar o clientelismo e de aproximar o cidadão do processo decisório.

A efetiva participação da população nos processos decisórios, como é o caso do Orçamento Participativo, que vem se constituindo como um mecanismo ampliado de engajamento da sociedade na gestão das políticas públicas, requer um esforço crescente de institucionalização da possibilidade de atendimento das demandas em bases negociadas. Trata-se de processar demandas e pressões e de implementar mecanismos formais que contemplem tanto os setores organizados e mobilizados, estimulando sua adequação à institucionalidade a partir do respeito à autonomia e à auto-organização, co- mo de envolvimento dos setores desorganizados. O Orçamento Participativo está legitimado e consta da agenda pública como mola propulsora do processo decisório da ação governamental (Jacobi, 1996). Isto está sendo construído dentro de uma lógica que não está apenas permeada pelo imediatismo e o utilitarismo, mas por uma radicalização da democracia, que, alargando os direitos de cidadania no plano político e social, constrói efetivamente novas relações entre governantes e governados. Este processo de gestão através do ingresso da cidadania organizada na máquina do Estado possibilita conhecer seu funcionamento e seus limites e estimula a construção de uma relação de co-responsabilização e de disputa, visando produzir consensos cada vez mais qualificados.

A experiência do Orçamento Participativo em Porto Alegre está diretamente vinculada com a capacidade que a administração local tem de criar canais legítimos de participação, combinando elementos da democracia representativa e de democracia participativa. Trata-se de uma experiência que tem se multiplicado, como referência da adoção de um processo participativo, baseado no conceito de esfera pública não-estatal que incide sobre o Estado, com ou sem o suporte da representação política tradicional.

Nesse contexto, a participação adquire uma linguagem e uma prática de ruptura com o corporativismo territorialmente determinado, com ênfase numa lógica presidida por uma abordagem universal da cidade, criando para os setores populares uma opção viável e altamente competitiva de participação política alternativa às práticas clientelistas. A distribuição das obras emerge de uma relação contratual previamente estabelecida através de um regulamento que determina as regras básicas de negociação interna de cada região da cidade e entre regiões, dificultando o clientelismo (Jacobi e Teixeira, 1996). Mas, apesar da sua repercussão positiva, também devem ser mostrados os seus limites, e estes residem, segundo os analistas, nas contradições associadas às dificuldades de ampliar a participação e à dependência em relação às autoridades municipais para estruturar a dinâmica de funcionamento (Navarro, 1999).

As dimensões diferenciadas de participação mostram a necessidade de superar ou conviver com certos condicionantes sociopolíticos e culturais, na medida em que o salto qualitativo começa a ocorrer a partir de diferentes engenharias institucionais, reforçando a importância de 
pensar a participação como um método de governo, o que pressupõe a realização de certas precondições necessárias à sua viabilização no nível do possível, dadas as características da cultura política brasileira.

Os complexos e desiguais avanços revelam que estas engenharias institucionais, baseadas na criação de condições efetivas para multiplicar experiências de gestão participativa que reforçam o significado da publicização das formas de decisão e de consolidação de espaços públicos democráticos, ocorrem pela superação das assimetrias de informação e pela afirmação de uma nova cultura de direitos. Estas experiências que denominamos inovadoras fortalecem a capacidade de crítica e de interveniência dos setores de baixa renda através de um processo pedagógico e informativo de base relacional, assim como a capacidade de multiplicação e aproveitamento do potencial dos cidadãos no processo decisório dentro de uma lógica não cooptativa. Isto mostra que existem condições favoráveis para cidadanizar a política, deslocando seu eixo do âmbito estatal para o cidadão.

Entretanto, estas experiências que inovam na relação entre Estado e sociedade civil ainda estão longe de representar um paradigma de significativa repercussão no atual quadro brasileiro, principalmente em virtude da falta de vontade política dos governantes e da fragilidade do tecido associativo. Os grupos organizados que interagem e pressionam, representam iniciativas fragmentárias que não atingem o cerne de uma sociedade refratária a práticas coletivas. A realidade brasileira é marcada por configurar um contexto de baixa institucionalização, no qual a maioria da população pouco se mobiliza para explicitar sua disposição de utilizar os instrumentos da democracia participativa visando romper com o autoritarismo social que prevalece.

A resposta a esta questão se torna ainda mais complexa na medida em que tomamos como uma referência possível e contraditória uma pesquisa sobre as práticas sociais face aos problemas ambientais na cidade de São Paulo (Jacobi, 1999). Os resultados mostram que mais de $80 \%$ dos moradores de São Paulo, quando consultados sobre o meio de ação mais efetivo para resolver os problemas ambientais no nível domiciliar e do bairro, indicam a ação governamental, sendo a opção pela ação comunitária quase sete vezes menor. Isto abre um estimulante campo de reflexão. Cabe ressaltar, entretanto, que, as respostas enfatizam a importância de o poder público exercer um papel nucleador e estruturador das ações no desempenho da função de informar e orientar através de campanhas educativas; fiscalizar e monitorar a execução de políticas públicas; e estimular uma dinâmica de co-responsabilização da comunidade na prevenção da desordem e degradação ambiental, configurando a existência de um potencial de oferta citadina orientada para uma atuação mais efetiva da defesa do interesse geral.

Os desafios para ampliar a participação estão intrinsecamente vinculados à predisposição dos governos locais de criar espaços públicos e plurais de articulação e participação, nos quais os conflitos se tornam visíveis e as diferenças se confrontam, como base constitutiva da legitimidade dos diversos interesses em jogo. A questão se refere ao papel do Estado como agente de controle ou participação, notadamente quanto à criação de um ambiente facilitador - capacidade de mobilizar energias e recursos da sociedade, estimulando diversos tipos de parcerias público/privado - e à garantia de implantação de políticas que privilegiam um estreito relacionamento entre eqüidade e participação. As possibilidades de reverter de forma significativa o atual quadro estão associadas, de um lado, à necessidade de uma reinvenção solidária e participativa do Estado. De outro, à difícil tarefa das organizações da sociedade civil, num contexto de erosão de direitos, de consolidar práticas que fortaleçam a sua capacidade de interlocução na definição de políticas públicas e na partilha dos recursos provenientes dos fundos públicos.

A alternativa da participação deve ser vista pela ótica dos níveis de concessão dos espaços de poder e, portanto, pela sua maior ou menor ruptura com estruturas tradicionais, patrimonialistas e autoritárias. Isto configura a possibilidade de os cidadãos assumirem um papel relevante no processo de dinamização da sociedade, e vem reforçar o exercício de um controle mais permanente e consistente dos usuários na gestão da coisa pública, sustentado no acesso à informação sobre o funcionamento do governo da cidade a todos os grupos sociais.

A possibilidade de criar as condições para a ruptura com a cultura política dominante e para uma nova proposta de sociabilidade baseada na educação voltada à participação se concretizará principalmente pela presença crescente de uma pluralidade de atores. Através da ativação do seu potencial de participação, esses atores terão cada vez mais condições de intervir consis- 
tentemente e sem tutela nos processos decisórios de interesse público, legitimando e consolidando propostas de gestão baseadas na garantia do acesso à informação, e na consolidação de canais abertos para a participação, que, por sua vez, são precondições básicas para a institucionalização do controle social.

A modernização dos instrumentos de gestão e de articulação requer uma engenharia socioinstitucional complexa apoiada em processos educativos e pedagógicos para garantir aos diversos atores envolvidos, notadamente aos grupos sociais mais vulneráveis, condições de acesso às informações em torno dos serviços de saneamento ambiental e dos impactos dos problemas ambientais.

O desafio que enfrenta é o de limitar, prevenir, minimizar e, se possível, eliminar os riscos através da disseminação de práticas sociais diversificadas. Isto implica a necessidade de multiplicação de iniciativas pautadas pela ampliação do direito à informação numa perspectiva integradora, assim como a formação de cidadãos, como portadores de um papel social constituído através da criação de espaços sociais de luta e na institucionalização de práticas de cidadania ativa que garantam a expressão e representação de interesses coletivos dos setores mais permeáveis à desigual distribuição dos riscos e da renda.

O desafio existente é o de superar as barreiras socioinstitucionais e fortalecer políticas pautadas pela inclusão da noção de interesse geral. Esta se concretiza na medida em que o tema da cidadania é assumido como um ponto nodal para a institucionalização da participação dos cidadãos em processos decisórios de interesse público. Para tanto, existe a necessidade de levar em consideração o nível de informação e/ ou desinformação dos moradores a respeito das necessárias inter-relações com os temas da cidade e seu envolvimento com uma perspectiva que enfatize o interesse geral. Este entendimento da questão pode ajudar a eliminar algumas das barreiras socioculturais que, freqüentemente, obstruem iniciativas formuladas para implantar melhoramentos no contexto urbano. Mas, que não são necessariamente bem-sucedidas, em virtude da falta de legitimidade e/ou consenso pelos diferentes atores relevantes, privados ou públicos, e que podem vir a ter um importante papel e impacto nos problemas e soluções.

No atual quadro urbano brasileiro, é inquestionável a necessidade de implementar políticas públicas orientadas para tornar as cidades social e ambientalmente sustentáveis, como uma forma de se contrapor ao quadro de deterioração crescente das condições de vida. Uma agenda para a sustentabilidade urbana deve ter como um dos seus objetivos gerar empregos com práticas sustentáveis e ampliar o nível de consciência ambiental, estimulando a população a participar mais intensamente nos processos decisórios como um meio de fortalecer a sua co-responsabilização no monitoramento dos agentes responsáveis pela degradação socioambiental.

Isto estimulará o fortalecimento das organizações sociais e comunitárias, a redistribuição de recursos através de parcerias, a disseminação de informação, e a capacitação para participar crescentemente dos espaços públicos de decisão e da construção de instituições pautadas por uma lógica de sustentabilidade. 


\section{Referências bibliográficas}

Arato A \& Cohen J 1994. Sociedade civil e teoria social. In Avritzer L. Sociedade civil e democratização. Del Rey, Belo Horizonte.

Avritzer L 1993. Cohen, Arato e Habermas: além da dicotomia Estado/mercado. Revista Novos Estudos CEBRAP vol. 36:213-222. CEBRAP, São Paulo.

Cunill Grau N 1998. Repensando o público através da sociedade. Editora Revan/ENAP, Rio de Janeiro, 299pp.

Jacobi P 1989. Movimentos sociais e políticas públicas. Cortez Editora, São Paulo, 175pp.

Jacobi P 1990. Descentralização municipal e participação dos cidadãos: apontamentos para o debate. Revista Lua Nova vol. 20:121-144.

Jacobi P 1996. Ação da Cidadania contra a Fome, a Miséria e pela Vida: um registro necessário. Revista Proposta, ano 23 no 67: 27-33.

Jacobi P 1999. Cidade e meio ambiente. Annablume Editora, São Paulo, 191pp.

Jacobi P 2000. Políticas sociais e ampliação da cidadania. FGV Editora, Rio de Janeiro, 152pp.
Jacobi P e Teixeira MA 1996. Orcamento participativo: o caso de São Paulo (1989-1992), à luz das experiências de Porto Alegre e Belo Horizonte. CEDEC, São Paulo, mimeo, 31pp.

Melucci A 1994. Movimentos sociais, renovação cultural e o papel do conhecimento. Entrevista feita por Avritzer, L. e Lyra, T. Revista Novos Estudos CEBRAP vol. 40: 152-166.

Navarro Z 1999. Democracia e controle social de fundos públicos: o caso do "orçamento participativo" de Porto Alegre (Brasil), pp. 293-334. In Bresser Pereira et al. (orgs.). O público não-estatal na reforma do Estado. Editora da Fundação Getúlio Vargas/CLAD, Rio de Janeiro.

Putnam R 1994. Making democracy work. Princeton University Press, Nova Jersey, 255pp.

Santos B 1996. Pela mão de Alice. Cortez Editora, São Paulo, 348pp.

Artigo apresentado em 5/1/2002

Versão final apresentada em 21/3/2002

Aprovado em 21/5/2002 